\title{
A STUDY ON CLINICAL PATTERNS OF PITYRIASIS VERSICOLOR AND SUSCEPTIBILITY OF MALASSEZIA SPECIES TO VARIOUS ANTIFUNGALS IN A TERTIARY CARE HOSPITAL IN PUDUCHERRY
}

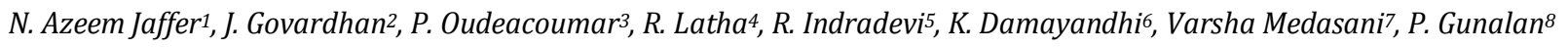 \\ 1 Final Year Postgraduate Student, Department of Dermatology, Aarupadai Veedu Medical College and Hospitals, Puducherry. \\ ${ }^{2}$ Assistant Professor, Department of Dermatology, Aarupadai Veedu Medical College and Hospitals, Puducherry. \\ ${ }^{3}$ Professor \& HOD, Department of Dermatology, Aarupadai Veedu Medical College and Hospitals, Puducherry. \\ ${ }^{4}$ Professor, Department of Microbiology, Aarupadai Veedu Medical College and Hospitals, Puducherry. \\ ${ }_{5}^{5}$ Associate Professor, Department of Dermatology, Aarupadai Veedu Medical College and Hospitals, Puducherry. \\ ${ }^{6}$ Assistant Professor, Department of Dermatology, Aarupadai Veedu Medical College and Hospitals, Puducherry. \\ ${ }^{7}$ Second Year Postgraduate Student, Department of Dermatology, Aarupadai Veedu Medical College and Hospitals, Puducherry. \\ 8Final Year Postgraduate Student, Department of Dermatology, Aarupadai Veedu Medical College and Hospitals, Puducherry.
}

\section{ABSTRACT}

\section{BACKGROUND}

Pityriasis versicolor is a superficial cutaneous fungal infection caused by Malassezia furfur, a dimorphic fungus. This study is undertaken to know various clinical patterns of disease, to culture and study the in vitro susceptibilities of Malassezia species to various antifungals.

\section{MATERIALS AND METHODS}

A cross sectional study of 100 patients with Pityriasis versicolor were evaluated clinically at a tertiary care hospital in Puducherry. The study period was 2 years. History and clinical examination was done and scraping samples were sent to Microbiology department for culture and sensitivity. Data was recorded accordingly.

\section{RESULTS}

Majority of the patients were young males. Most of the patients had asymptomatic hypopigmented macules over face and neck. Most of the patients use synthetic clothing and shown exacerbation during summer months. Recurrence is rare. Majority of patients show mild to moderate scaling. Seborrheic dermatitis and acne vulgaris are the most common associated dermatoses. Majority were $\mathrm{KOH}$ and Woods lamp positive. Sixty-seven patients were culture positive and most of patients show M. furfur colonies and all patients are sensitive to the three common antifungals.

\section{CONCLUSION}

Overall, our study shows $\mathrm{M}$. furfur is the most common isolated species and all are sensitive to the three commonly used antifungals: Fluconazole, Itraconazole and Ketoconazole. Hence, Malassezia species has not developed resistance against these drugs in our study area, and they can be used successfully in treatment of Pityriasis versicolor.

\section{KEYWORDS}

Pityriasis Versicolor, Malassezia Furfur, KOH, Woods Lamp, Antifungals.

HOW TO CITE THIS ARTICLE: Jaffer NA, Govardhan J, Oudeacoumar P, et al. A study on clinical patterns of pityriasis versicolor and susceptibility of malassezia species to various antifungals in a tertiary care hospital in Puducherry. J. Evolution Med. Dent. Sci. 2017;6(10):761-764, DOI: 10.14260/Jemds/2017/165

\section{BACKGROUND}

Pityriasis versicolor is a cutaneous, superficial fungal infection due to colonization of stratum corneum by a dimorphic fungus known as Malassezia furfur. ${ }^{1}$ It is more prevalent in tropical region due to the relative high temperature and humidity. ${ }^{2}$ Clinically, the disease is usually asymptomatic with hypo or hyper pigmented macules or patches.

Financial or Other, Competing Interest: None.

Submission 26-12-2016, Peer Review 19-01-2017,

Acceptance 25-01-2017, Published 02-02-2017.

Corresponding Author:

Dr. N. Azeem Jaffer,

Final Year $P G$

Department of Dermatology,

Aarupadai Veedu Medical College and Hospitals,

Kirumampakkam,

Puducherry-607402.

E-mail: jaffer.azeem@gmail.com

DOI: $10.14260 /$ jemds $/ 2017 / 165$ (c) (i) $\odot$
Usually, the patient seeks medical attention for cosmetic blemishes. Wood's lamp examination usually shows yellowish fluorescence of the involved skin. ${ }^{3}$ The organism can readily be identified by treating skin scraping with $10 \%$ $\mathrm{KOH}$. The fungi appear as short, thick hyphae with a large number of spores (spaghetti and meat-ball appearance). ${ }^{3}$ Culture and molecular analysis of Malassezia microflora may be used to identify different Malassezia species. ${ }^{4}$ Currently, twelve different species of Malassezia have been described. ${ }^{5}$ There are a number of treatment options, topical and systemic therapies for pityriasis versicolor. This study is undertaken to know "clinical patterns of the disease with respect to morphology, distribution, epidemiological factors like age, sex distribution and seasonal variation of the disease, and to culture \& study the in vitro susceptibilities of Malassezia species to various antifungals".

\section{MATERIALS AND METHODS}

One hundred patients of Pityriasis versicolor were selected from those attending the outpatient department of 
Dermatology, Venereology and Leprosy at Aarupadai veedu medical college and hospital, Puducherry from October 2014 to September 2016.

It is a cross sectional study. All newly diagnosed, untreated male and female patients attending Dermatology OPD (Out Patient Department) with pityriasis versicolor were selected and included in the study after taking consent. Previously diagnosed and treated cases were excluded. The study was approved by the Institutional Ethical Committee A detailed history was taken with particular reference to onset, duration, symptoms, clothing and associated dermatoses were recorded.

Factors like seasonal variation, family history and presence of any associated dermatologic illnesses were noted. A thorough clinical examination was done with reference to the site, colour, extent of the lesion, number and type of lesions and the details were recorded.

$\mathrm{KOH}$ examination and Wood's lamp examination were done in all patients before therapy.

Skin scrapings were sent to Microbiology department for Culture (Using HiCrome Malassezia agar) \& sensitivity (Using E-strips) and results were recorded accordingly.

\section{RESULTS}

Of a total of 100 patients included in our study, the disease was found to be highly prevalent in patients belonging to the second and third decades of life (60\%) and occurred in men more, when compared to females. (M: F ratio is 2.1:1). A positive family history was observed and it accounted to $13 \%$ in this study.

Most of the patients were asymptomatic (71\%) and came to hospital for cosmetic concern.

Majority of the lesions were on the face \& neck (68\%), back (31\%) and chest (28\%) [Graph 1]. The disease showed an exacerbation especially in the summer months (60\%).

Most of the lesions were hypopigmented (69\%) macules $(63 \%)$. Recurrence was a problem in a small group of patients (11\%). The most common associated dermatoses were seborrhoeic dermatitis and acne vulgaris. 56\% had mild scaling, $30 \%$ had moderate scaling and $14 \%$ had severe scaling.

KOH examination was positive in $98 \%$ of the cases. $74 \%$ of patients showed yellowish fluorescence on Woods lamp.

Sixty-seven patients were culture positive and among them 44 showed M. furfur colonies and 23 showed M. globosa colonies [Graph 2]. All 67 culture positive patients were found to be susceptible to the three commonly used antifungals- Fluconazole, Itraconazole and Ketoconazole.

\begin{tabular}{|c|c|c|}
\hline & Present (\%) & Absent (\%) \\
\hline Itching & 29 & 72 \\
\hline Recurrence & 11 & 89 \\
\hline Summer exacerbation & 60 & 40 \\
\hline Synthetic clothes usage & 54 & 46 \\
\hline Positive family history & 13 & 87 \\
\hline Woods lamp fluorescence & 74 & 26 \\
\hline KOH positive & 98 & 2 \\
\hline Culture positive & 67 & 33 \\
\hline \multicolumn{3}{|c|}{ Table 1. Results of the Study } \\
\hline
\end{tabular}

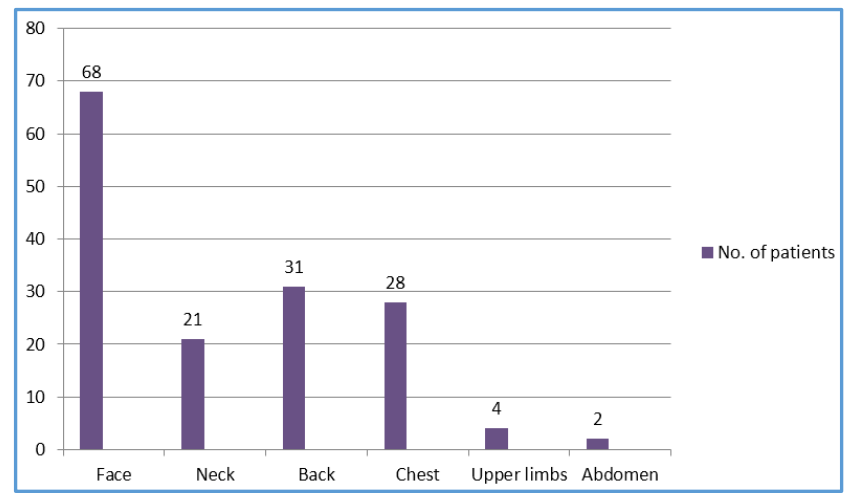

Graph 1. Showing Distribution of Lesions

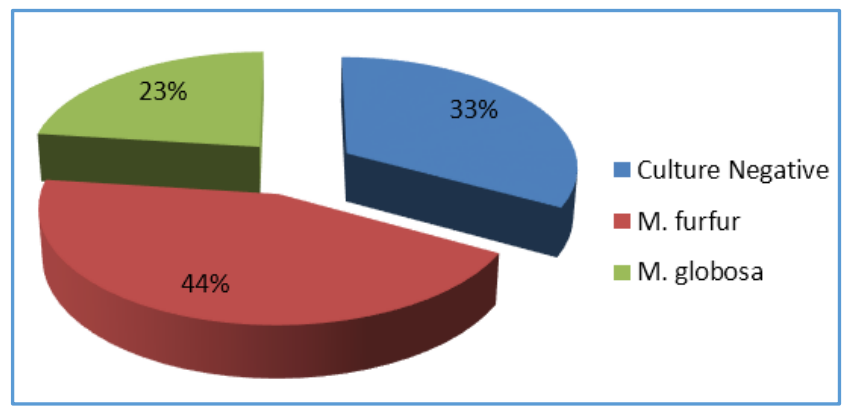

Graph 2. Culture \& Species Identification

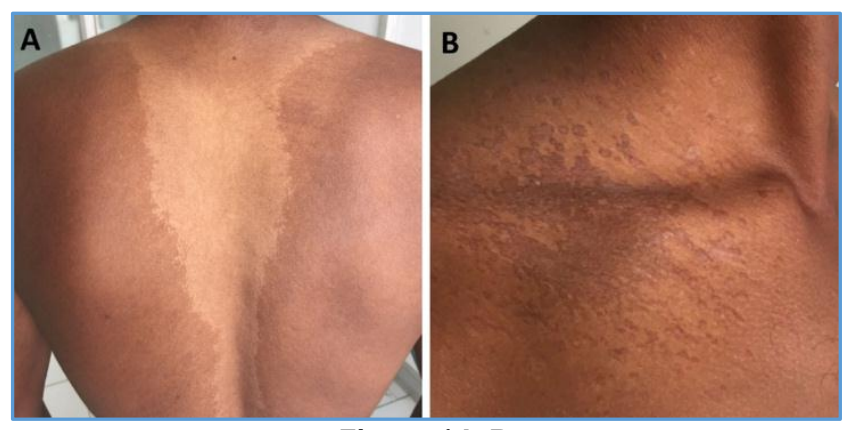

Figure 1A, $B$

Figure 1A. Pityriasis versicolor (Hypopigmented) over the back.

Figure 1B. Pityriasis versicolor (Hyperpigmented) of shoulder region extending to the upper chest

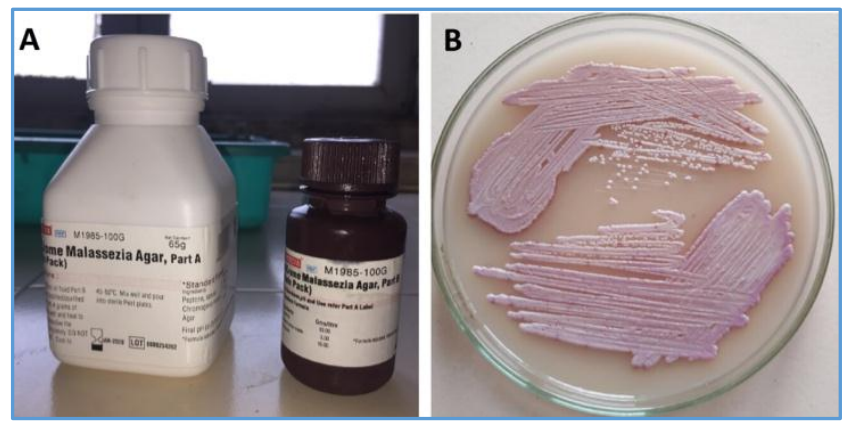

Figure $2 A, B$

Figure 2A. HiCrome Malassezia agar- Twin pack.

Figure 2B. Culture of Malassezia furfur on HiCrome agar showing mauve colour colonies. 

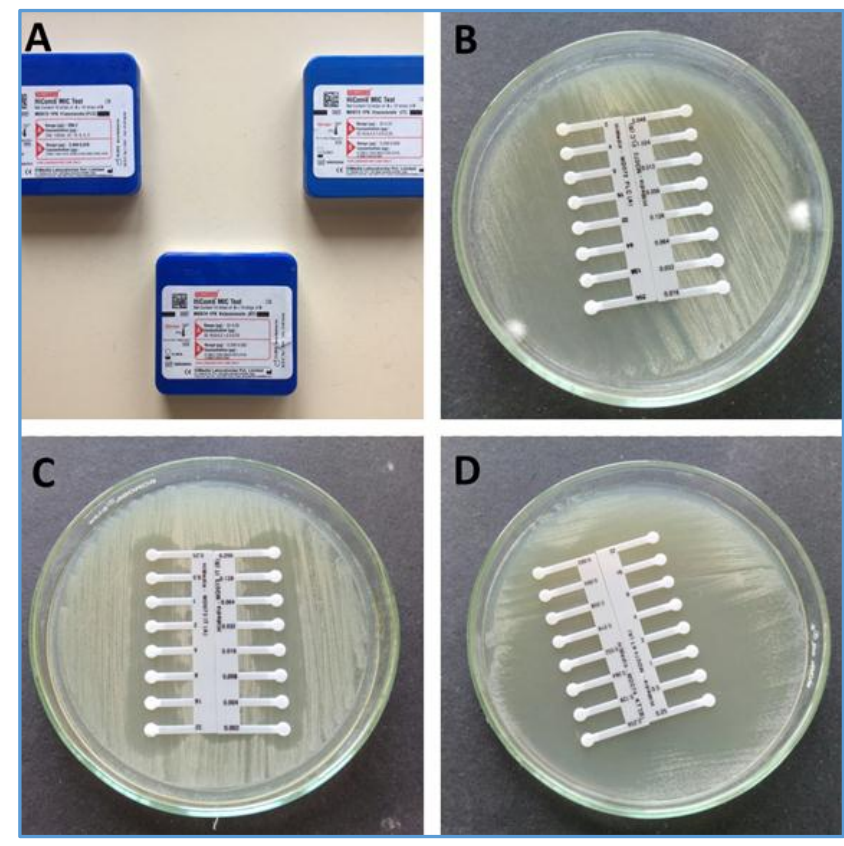

Figure $3 A, B, C, D$

Figure 3A. HIMEDIA- HiCrome strip packs for sensitivity tests.

Figure 3B. Antifungal susceptibility of M. furfur against Fluconazole.

Figure 3C. Antifungal susceptibility of M. furfur against Itraconazole.

Figure 3D. Antifungal susceptibility of M. furfur against Ketoconazole.

\section{DISCUSSION}

This study done at tertiary care centre provided number of facts of them, many had a good correlation with the studies conducted by previous workers.

The most affected age group in this study belonged to the age group of 21 to 30 years (36\%) followed by $11-20$ years (24\%). Similar results were observed by Guillot et al ${ }^{6}$ In his study, he inferred that, most patients had manifested disease during puberty or thereafter and found it to be less frequent over 50 years of age. ${ }^{6}$ Cullen, ${ }^{7}$ Michalowski et al, ${ }^{8}$ Terragni et $\mathrm{al}^{9}$ have also observed that pityriasis versicolor is uncommon before puberty. Accounting to, the changes in the skin sebum levels.

In our study, the prevalence of disease was more among males accounting to $68 \%$ when compared to females (32\%).

Rao et al ${ }^{10}$ Maheshwariamma, and Singh et al ${ }^{11}$ have also observed almost similar results with more prevalence of cases in males. This probably could be attributed to their occupation and outdoor activities.

Thus, the gender prevalence in the present study is in concurrence with the observations made by other authors.

In our study, 29 patients had clinical features of itching, while the rest (71) of them were asymptomatic. Gupta et al ${ }^{12}$ also had similar observation in their study and they opined that majority of patients were asymptomatic and they were chiefly of cosmetic concern. Thus, the result of the present study has good agreement with the above study.
In this study, $11 \%$ of patients had recurrence of lesions. Almost similar result was opined by the study done by Gatha S. Rao. Recurrence was attributed to persistence of the yeast in the deeper part of hair follicle. ${ }^{11}$

In the present study, 60 patients had exacerbation in summer while remaining didn't show any seasonal variation.

Klenk et al ${ }^{13}$ has observed that Tinea versicolor is more frequently seen in humid, warm climates or in the tropics than in dry cold zones. Rao et al, has also found that, $35 \%$ of the patients had the disease first in summer and this could probably be due to increased sweating. There by, predisposing the person to the infection. ${ }^{14}$ The results of the present study concurred well with the above mentioned studies.

In our study, the incidence of tinea versicolor in patients using synthetic clothing was more (54\%). Similar result was observed in the study done by Singh G. ${ }^{11}$

In the present study 13 patients had history of similar complaints in the family. Rao et $\mathrm{al}^{10}$ found a positive family history in $38.30 \%$ of patients, out of whom $10 \%$ gave history in spouses and $13.30 \%$ in parents. Whereas, Tschen ${ }^{15}$ has observed that there is little evidence that the disease is highly contagious, since only $7.5 \%$ of cases are present in the same couples living together. Thus the various factors attributable to the existence of the disease in the family are variable.

In the present study $68 \%$ showed macules, $4 \%$ had patches, follicular lesions were seen in $3 \%$ and mixed variety of lesions (macules, patches and follicular) were seen in almost $25 \%$ of patients. Rao et al ${ }^{10}$ found macular lesions in $86.60 \%$ of patients, follicular in $6.60 \%$ of patients, confluent in $10 \%$ of the patients and guttate in $1.60 \%$ of patients whereas Assaf and Weil, 16 found patchy lesions more in their study.

In our study, 69 patients had hypopigmented lesions, 20 had hyperpigmented lesions, 11 patients had both hypo and hyperpigmented lesions. Assaf and Weil ${ }^{16}$ have observed that lesions typically begin as reddish macules later becoming hypopigmented, and hyperpigmentation occurs occasionally which may be due to individual differences in the inflammatory response.

In our study, 56 patients had mild scaling, 30 had moderate scaling and 14 patients had severe scaling. Assaf and Weil 16 have found scaling in all the patients in their study. Similarly, Tschen ${ }^{15}$ found the scaling to be fine and greasy in all their patients. In the present study, 68 patients had lesions on the face, 21 had lesions over the neck, 31 over back, 28 over chest, 4 patients shown lesions over the upper limb and 2 over their abdomen. Gupta et al ${ }^{14}$ found the lesions to be more often on lipid rich areas of the body like the face, neck and the trunk. Similarly, Assaf and Weil ${ }^{16}$ found the trunk, arms, neck to be the commonly affected sites. Rao et al ${ }^{10}$ found the disease in $71.6 \%$ over the neck, $70 \%$ over the back and $58.30 \%$ over the chest.

Hence, the distribution of the lesions in our present study is different from the observation made by other authors.

In the present study, 7 patients showed associated seborrhoea, 6 showed acne, 3 had tinea corporis and 10 patients had miliaria, ichthyosis, alopecia, atopy, vitiligo, P. rosea, DPN, skin tag, senile pruritis and psoriasis (each one respectively), while the remaining 75 patients did not have any associated dermatological illness. Assaf and Weil 16 have 
mentioned common association between pityriasis versicolor and seborrheic dermatitis as the two conditions, which disappear significantly with azole antifungals. Tschen ${ }^{15}$ found seborrheic dermatitis, hyperhidrosis, psoriasis and atopic dermatitis co-exist frequently with pityriasis versicolor. Rao et al 10 found seborrheic dermatitis in $11.60 \%$ of their patients who had tinea versicolor.

Ninety-eight patients showed positive $\mathrm{KOH}$ examination. Rao et $\mathrm{al}^{10}$ in their study of 120 patients, found positive $\mathrm{KOH}$ results in $46.6 \%$ of the patients. In the present study, 74 patients showed fluorescent lesions. Savin has found positive Wood's lamp examination in $1 / 3^{\text {rd }}$ of patients. Hence, our findings of Wood's lamp examination concur well with the studies conducted by Savin. In the present study, 67 patients were culture positive showing mauve colonies on agar. The remaining 33 patients did not show any growth on culture plates and hence considered as Culture negative. Among the 67 culture positive patients, 44 of them show M. furfur colonies and the remaining 23 show $\mathrm{M}$. globosa colonies. In a study conducted by Parveneh Afshar in Sari, Iran, 74.6\% of the patients showed Malassezia species in culture. M. globosa $(54 \%)$ was found to be the predominant pityriasis versicolor isolate, followed by M. furfur (32\%), and other species. ${ }^{17}$ Thus, our culture finding correlates with the above study, but in contrast, M. furfur is the most common species than M. globosa in our study.

\section{CONCLUSION}

We conclude that Pityriasis versicolor is the most common chronic, mild, usually asymptomatic superficial fungal infection of the tropical climate. All species respond to the three most commonly used antifungals. Hence, it is evident that the Malassezia species has not developed resistance against these common drugs in our study area till now, and they can be used successfully in treatment of Pityriasis versicolor.

\section{REFERENCES}

[1] Michalowski R, Rodziewicz H. Pityriasis versicolor in children. Br J Dermatol 1963;75(10):397-400.

[2] Maheswariamma S. Clinical and epidemiological studies on tinea versicolor in Kerala. Indian J Dermatol Venereal Leprol 1978;44(6):345-51.

[3] Savin R. Diagnosis and treatment of tinea versicolor. J Fam Pract 1996;43(2):127-132.
[4] Gupta AK, Boekhout T, Theelen B, et al. Identification and typing of malassezia species by amplified fragment length polymorphism and sequence analyses of the internal transcribed spacer and large-subunit regions of ribosomal DNA. J Clin Microbiol 2004;42(9):4253-60.

[5] Guillot J, Guého E, Lesourd M, et al. Identification of malassezia species. A practical approach. J Mycol Med 1996;6(3):103-10.

[6] Gueho E, Midgley G, Guillot J. The genus malassezia with description of four new species. Antonie Van Leeuwenhoek 1996;69(4):337-55.

[7] Cullen SI. Age of patients with pityriasis versicolor. J Am Acad Dermatol 1983;9(3):464-65.

[8] Michalowski R, Rodziewicz H. Pityriasis versicolor in the aged. Br J Dermatol 1965;77(7):388-90.

[9] Terragni L, Lasagni A, Oriani A, et al. Pityriasis versicolor in the pediatric age. Peidatr Dermatol 1991;8(1):9-12.

[10] Rao GS, Kurvilla M, Kumar P. Clinico-epidemiological studies on tinea versicolor. Indian J Dermatol Venereol Leprol 2002;68(4):208-9.

[11] Singh G, Gour KN, Dikshit KS, et al. Clinical pattern of pityriasis versicolor. Indian J Dermatol Venereol Leprol 1966;32(3):81-84.

[12] Gupta AK, Batra R, Bluhm R, et al. Skin diseases associated with malassezia species. J Am Acad Dermatol 2004;51(5):785-98.

[13] Klenk AS, Martin AG, Heffferman MP. Yeast infections; candidiasis pityriasis (tinea) versicolor. In : Freedberg $\mathrm{IM}$, Eisen AZ, Wolff $\mathrm{K}$, et al, eds. Dermatology in general medicine. $6^{\text {th }}$ edn. Vol. 2. New York: McGraw Hill 2003:2006-20.

[14] Gupta AK, Batra R, Bluhm R. Pityriasis versicolor. Dermatol Clin 2003;21(3):413-29.

[15] Tschen EH. Clinical aspects of superficial fungal infections. Dermatol Clin 1984;2(1):3-18.

[16] Assaf RR, Weil ML. The superficial mycoses. Dermatol Clin 1996;14(1):57-67.

[17] Afshar P, Ghasemi M, Kalhori S. Identification of malassezia species isolated from patients with pityriasis versicolor in Sari, Iran, 2012. Jundishapur Journal of Microbiology 2013;6(6);e8581. 